\title{
Impact of adolescent health education on adolescent girls in rural schools and colleges
}

\author{
Jyoti S. Ghongdemath ${ }^{1}$, Ashwini Sidhmalswamy ${ }^{2}$, Ashalata A. Mallapur ${ }^{1}$, \\ Vishwanath V. Shindholimath ${ }^{3}$
}

\author{
${ }^{1}$ Department of Obstetrics and Gynecology, S.N. Medical College, Bagalkot, Karnataka, India \\ ${ }^{2}$ Department of Obstetrics and Gynecology, Vydehi Institute of Medical Sciences \& Research Centre, Bengaluru, \\ Karnataka, India \\ ${ }^{3}$ Department of Surgery, S.N. Medical College, Bagalkot, Karnataka, India
}

Received: 07 December 2015

Accepted: 12 December 2015

\section{*Correspondence:}

Dr. Jyoti S. Ghongdemath,

E-mail: jsgv.vd@gmail.com

Copyright: (c) the author(s), publisher and licensee Medip Academy. This is an open-access article distributed under the terms of the Creative Commons Attribution Non-Commercial License, which permits unrestricted non-commercial use, distribution, and reproduction in any medium, provided the original work is properly cited.

\begin{abstract}
Background: Adolescence is a transitional phase linking childhood to adulthood. Among adolescents, girls are especially vulnerable and more susceptible biologically to reproductive tract infections. In rural India, health education given to these girls, builds knowledge, motivates them to improve and maintain their health, prevent disease and reduce risky behaviors. This study aims to evaluate the impact of adolescent health education on these rural teenage girls.

Methods: This is a school-based educational interventional study on adolescent health education, on the girls 11 to 19 years old, in our area, during the period from January 2012 to February 2014. A pretest and post-test were done along with the health education, which covered various topics concerning adolescent health.

Results: There were 1249 girl students enrolled into the study. The knowledge on menstruation and menstrual hygiene improved significantly after health education. The awareness of ill effects of child marriage, consanguineous marriage and teenage pregnancy was known by only $82.9 \%, 29.5 \%$ and $5.8 \%$ respectively. The knowledge about selfbreast examination, Pap smears and awareness that chronic white discharge after marriage, leads to cancer of cervix in the long run, were known by none. By this study, it is seen that their knowledge was poor during pretest and remarkable improvement took place after the educational intervention.

Conclusions: This study shows the feasibility of adolescent health education program implementation on girls in the rural schools.
\end{abstract}

Keywords: Adolescent health education, Adolescent girls, Rural school girls

\section{INTRODUCTION}

Adolescence is an important and sensitive phase of life. According to the World Health Organisation, adolescence is defined as the period between 10 and 19 years. ${ }^{1}$

Adolescence is a transitional phase linking childhood to adulthood. Many physical, mental and social developments take place during this phase. Adolescent girls constitute about one fifth of the world's female population. $^{2}$ India has the largest population of adolescents in the world, being home to 253 million adolescents, constituting $20 \%$ of Indian population, according to 2011 census. Also, it constitutes $20 \%$ of the world's 1.2 billion adolescents.

For a girl, adolescence is transformation into a woman and menstruation, which is unique to the females, is a 
milestone. Among adolescents, girls are especially vulnerable and more susceptible biologically to reproductive tract infections. In rural India, due to lack of education, gender inequality, girls are forced into early marriage, early child bearing, violence and sexual abuse. Menstruation is generally regarded as unclean in the rural society. The ignorance and conservative outlook of the rural society, make things worse by neglecting the female child. They think it is a taboo to openly discuss the issues of adolescence, which keeps these rural teenage girls away from the appropriate knowledge regarding their health and hygiene, making them prone to infections ${ }^{3}$. The knowledge and practices about menstrual hygiene among rural adolescent girls is very poor as shown by many studies done in India. ${ }^{3-6}$ Menstrual disorders are found to be the commonest gynaecological problem in teenagers, ${ }^{7}$ affecting their future reproductive health if ignored. They are also at risk of many diseases due to poor sanitation, unclean water and lack of personal hygiene. Many may even drop schooling after primary education. Hence, catching them young and imparting adolescent health education to these rural teenage girls in schools is important and better if it is also reinforced and continued in the pre university and undergraduate colleges too; as revision at every level will certainly refresh their knowledge. In schools, as moral education is important, so also is health education for adolescents. Brigham Young, an American leader, aptly said- You educate a man; you educate a man. You educate a woman; you educate a generation. Health education builds knowledge, motivates students to improve and maintain their health, prevent disease and reduce risky behaviours.

This study aims to evaluate the impact of adolescent health education on teenage girls in rural schools and colleges; to frame, follow and study the feasibility to incorporate it, in the school curriculum. Also to assess the effect of various aspects of this type of health education, in terms of immediate improvement of knowledge, in the nutritional, physical, psychological, reproductive and social health.

\section{METHODS}

This is a school-based educational interventional study on adolescent health education, on the girls 11 to 19 years old, in our area, during the period from January 2012 to February 2014. We included school girls from grade $6^{\text {th }}$ to $10^{\text {th }}$, selecting randomly 2 English medium schools, 1 Kannada medium school and college girls 17 to 19 years old, from pre-university and first year degree colleges from the surrounding rural areas. Total girl students were 1270 and all were day scholars. Out of them 1249 participated and 7 were absent due to ill-health and the rest were either shy to take the test or didn't want to open-up on the topic. A team of two consultants along with 2 teachers from each school were involved in this study. Ethical committee clearance from the institute was taken. Permission from the principals of these institutions was taken. Verbal consent was taken from the girls after explaining them the aim of the study and ensuring confidentiality.

\section{Pre test}

This consisted of a questionnaire to test the level of knowledge and also was used to identify the learning needs of the adolescent girls. The questionnaire was designed in English and Kannada, having questions set on various aspects of adolescent health. It was supposed to be answered by the girls before the health education lecture given by the consultants. The teacher hands out the questionnaire in the classroom and the girls are supposed to write their answers honestly without discussing and were collected back. Male students are not allowed into the classroom during this program. The questionnaire included baseline characteristics of the study population including socio-demographics and knowledge on adolescent changes, menstruation and hygiene, its associated problems, nutrition and common diseases, marriage, pregnancy, contraception and female cancers. Intervention: The adolescent health education was then given the next day after evaluating the answers and noting the areas which needed to be stressed upon, during the lecture. The health educational lecture of 120 minutes, was given by the consultants and were didactic, having audio visual aids and interactive sessions to clarify their doubts. The various topics on adolescent health were physiological changes in adolescence, reproductive system, menstruation, hygienic menstrual practices, do's and don'ts, use of clean cotton pads, proper pad disposal, right method of perineal wash, menstrual problems and solutions, white discharge, breast lumps, when to see the gynecologist; importance of nutrition and physical exercise, common diseases in the community; ideal age of marriage; facts of child marriage, consanguineous marriage and teenage pregnancy; pregnancy- cause and care, contraception, population explosion, sexually transmitted diseases including HIV; awareness of common cancers in females like cancer of cervix, breast cancer and of preventive aspects like vaccination before marriage, against viruses causing cancer of cervix, undergoing PAP tests after marriage as recommended by gynecologists, as cancer of cervix is the commonest cancer in females in India. The other topics included addiction to drugs, smoking, alcohol; road traffic accidents; value of learning good virtues, awareness on 'good and bad touch'; breaking the silence to raise voice against social evils like dowry, female infanticide, violence on females and gender inequality. All the girls were made to take a common pledge at the end of the lecture, to follow always, all that is taught to them in this session and each one should teach one, either a family member or a friend or neighbour, to spread the knowledge. Post-test: The effect of the health educational intervention was evaluated immediately following intervention, with a post test. They had to take the questionnaire test again. 
The data was analysed using proportions and percentages. Chi square test was used to test the post-test knowledge improvement.

\section{RESULTS}

Of the 1249 girl students enrolled into the study, around $10.4 \%$ of the school girls were in the age group 12-13 years and among college girls $20 \%$ were in 16-17 years age group (Table 1). Ninety two percent were Hindus. A majority of the parents were literate. Seventy one percent were from low socio-economic group. Most of them had their first menses between 13 to 14 years.

Table 1: Age distribution of the students.

\begin{tabular}{|lll|}
\hline Age(years) & Numbers & $\%$ \\
\hline $11-12$ & 116 & 9.2 \\
\hline $12-13$ & 131 & 10.4 \\
\hline $13-14$ & 124 & 9.9 \\
\hline $14-15$ & 128 & 10.2 \\
\hline $15-16$ & 127 & 10.1 \\
\hline $16-17$ & 250 & 20 \\
\hline $17-18$ & 244 & 19.5 \\
\hline $18-19$ & 129 & 10.3 \\
\hline
\end{tabular}

Knowledge prior to menses was $52.6 \%$. The girls had a fair knowledge regarding menstruation and menstrual hygiene at pre-test (Table 2). Most of them didn't know that pregnancy causes missed periods too. The knowledge on menstruation and menstrual hygiene improved significantly from $69.3 \%$ to $96.9 \%$ and $64.9 \%$ to $100 \%$ respectively after health education.

Table 2: Knowledge regarding menstruation and hygiene.

\begin{tabular}{|lllll|}
\hline Facts & Pre-test & \multicolumn{2}{l}{ Post-test } \\
\hline & No. & $\%$ & No. & $\%$ \\
\hline Cause of menstruation & 578 & 46.2 & 1211 & 96.9 \\
\hline $\begin{array}{l}\text { Proper use of pads \& } \\
\text { disposal }\end{array}$ & 866 & 69.3 & 1249 & 100 \\
\hline Bath during menses & 949 & 75.9 & 1249 & 100 \\
\hline $\begin{array}{l}\text { Genital wash \& hand } \\
\text { wash }\end{array}$ & 811 & 64.9 & 1249 & 100 \\
\hline $\begin{array}{l}\text { Common Menstrual } \\
\text { problems and solutions }\end{array}$ & 436 & 34.9 & 988 & 79.1 \\
\hline
\end{tabular}

The fact that fertilization leads to pregnancy was not known to many (Table 3). The awareness of ill effects of child marriage, consanguineous marriage and teenage pregnancy was known by only $82.9 \%, 29.5 \%$ and $5.8 \%$ respectively (Table 4). The importance of nutrition during adolescence and during pregnancy and lactation was known by little more than half of the students. The awareness about good \& bad touch was known by $52 \%$ and contraception by $4.7 \%$. The awareness about cancer of breast was known by only $3.2 \%$. But the knowledge about self-breast examination, Pap smears and awareness that chronic white discharge after marriage, leads to cancer of cervix in the long run, were known by none (Table 5).

Table 3: Awareness of physiology, reproductive system \& infections.

\begin{tabular}{|lllll|}
\hline \multirow{2}{*}{ Facts } & \multicolumn{3}{l}{ Pre-test } & \multicolumn{2}{l|}{ Post-test } \\
\cline { 2 - 5 } & No. & $\%$ & No. & $\%$ \\
\hline $\begin{array}{l}\text { Common puberty } \\
\text { changes }\end{array}$ & 852 & 67 & 1249 & 100 \\
\hline Breast lumps & 51 & 04 & 1249 & 100 \\
\hline Reproductive system & 1110 & 87.4 & 1249 & 100 \\
\hline Fertilization & 657 & 52.6 & 1249 & 100 \\
\hline White discharge & 749 & 59.9 & 949 & 75.9 \\
\hline $\begin{array}{l}\text { Sexually transmitted } \\
\text { diseases }\end{array}$ & 54 & 04.3 & 1111 & 88.9 \\
\hline
\end{tabular}

Table 4: Awareness about marriage, pregnancy and contraception.

\begin{tabular}{|lllll|}
\hline Facts & Pre-test & \multicolumn{2}{l|}{ Post-test } \\
\hline & No. & $\%$ & No. & $\%$ \\
\hline Ideal age of marriage & 1149 & 92 & 1249 & 100 \\
\hline Child marriage & 1036 & 82.9 & 1249 & 100 \\
\hline $\begin{array}{l}\text { Consanguineous } \\
\text { marriage }\end{array}$ & 369 & 29.5 & 1249 & 100 \\
\hline Pregnancy care & 711 & 56.9 & 1199 & 95.9 \\
\hline Teenage pregnancy & 73 & 05.8 & 1249 & 100 \\
\hline Contraception options & 59 & 04.7 & 920 & 73.6 \\
\hline $\begin{array}{l}\text { 2-child/small family } \\
\text { norm }\end{array}$ & 918 & 73.4 & 1249 & 100 \\
\hline
\end{tabular}

Table 5: Awareness about female cancers, its prevention \& general health.

\begin{tabular}{|lllll|}
\hline \multirow{2}{*}{ Facts } & \multicolumn{2}{l}{ Pre-test } & \multicolumn{2}{l|}{ Post-test } \\
\hline & No. & $\%$ & No. & $\%$ \\
\hline Pap smears & 0 & 0 & 921 & 73.7 \\
\hline Self breast examination & 0 & 0 & 800 & 64 \\
\hline $\begin{array}{l}\text { Cancer of cervix \& } \\
\text { vaccination }\end{array}$ & 0 & 0 & 848 & 67.8 \\
\hline Cancer of breast & 40 & 03.2 & 940 & 75.2 \\
\hline Nutrition \& exercise & 750 & 60 & 1110 & 88.8 \\
\hline Communicable diseases & 830 & 66.4 & 1249 & 100 \\
\hline Addiction \& accidents & 957 & 76.6 & 1249 & 100 \\
\hline Good \& bad touch & 645 & 51.6 & 1249 & 100 \\
\hline Female infanticide & 814 & 65.1 & 1249 & 100 \\
\hline Other social evils & 628 & 50.2 & 1249 & 100 \\
\hline
\end{tabular}

By this study, it is seen that their knowledge was poor during pretest and remarkable improvement took place after the educational intervention $(\mathrm{p}<0.0001)$. 


\section{DISCUSSION}

Our study evaluates the impact of adolescent health education on the adolescent school and college girls in a taluka place. This study also imparted health education to these girls at this young age, so that, this will be carried along into their future life too; as most of the rural girls might discontinue their studies after primary education. So it is very important to incorporate this into the school curriculum right from middle school level itself and also the teachers get trained in this regard. The socio economic status also influences their knowledge. Educating the mothers of the teenage girls will certainly help too.

Most of the studies were regarding menstrual health, few were related to reproductive health but our study was regarding adolescent health as a whole, including various aspects like reproductive health, nutrition, exercises, female cancers, social health, women empowerment through their health improvement etc.

As seen in our study, few studies in the recent years too have shown the effectiveness of such educative interventions which increased the knowledge of reproductive health. ${ }^{1,8}$ The studies conducted in developing countries also prove the efficacy of such intervention in improving their knowledge in various aspects of reproductive health. ${ }^{9-13}$ The studies conducted in various schools in many talukas and districts in India, ${ }^{2-}$ 4,14-16 showed poor knowledge and practices regarding menstruation and health among teenagers. The results of our study are also comparable.

Lifestyle modifications including regular physical exercises, reducing intake of unhealthy junk food was emphasized to improve menstrual health which was also done in another study. ${ }^{17}$ The knowledge, practices and sanitary facilities were less in these rural girls as seen from the pre test, in our study, which is similar to another study which compared the same between rural and urban adolescent girls and came to the same conclusion. ${ }^{18}$

Definitely, there is a strong impact of adolescent health education on rural teenage girls. It inculcates good practices and habits to lead a healthy life, right from their teenage, taking their life in control after knowing in reality, 'health is wealth'.

\section{CONCLUSIONS}

The positive results of this study show the feasibility of adolescent health education program implementation in the rural schools, the target group, especially standards 6 th to 12 th. This will ensure the health of the girls, which can be regarded as the index of a healthy society. In addition to imparting such education to the teenage girls and teachers, extending it to their family members, especially mothers, will be a blessing in disguise.

\section{ACKNOWLEDGEMENTS}

Our thanks are due to all the students, teachers and the Principals of the various schools \& colleges. We are very grateful for the support given by the management committee of these institutions.

Funding: No funding sources

Conflict of interest: None declared

Ethical approval: The study was approved by the Institutional Ethics Committee

\section{REFERENCES}

1. Rao R, Lena A, Nair NS, Kamath V, Kamath A. Effectiveness of reproductive health education among rural adolescent girls: A school based intervention study in Udupi Taluk, Karnataka. Indian J Med Sci. 2008;62:439-43.

2. Bharathalakshmi J, Govindarajan PK, Ethirajan N, Felix AJW. Knowledge and practice of menstrual hygiene among school going adolescent girls. National Journal of Research in community medicine. 2014;3(2):138-42.

3. Thakre SB, Thakre SS, Reddy M, Rathi N, Pathak K, Ughade S. Menstrual hygiene: Knowledge and practice among adolescent school girls of Saoner, Nagpur District. Journal of Clinical and Diagnostic Research. 2011;5(5):1027-33.

4. Abhay BM, Naveeta K, Gargi AM, Ramachandra CG. A cross-sectional study on awareness regarding safe and hygienic practices amongst school going adolescent girls in rural area of Wardha District, India. Global Journal of Health Science. 2010;2(2):225-31.

5. Khan A. Perceptions and practices about menstrual hygiene among adolescent girls in a rural area- A cross sectional study. International Journal of Health Sciences and Research. 2012;2(8):29-34.

6. Singh AK, Bandhani A, Nidhi M. Knowledge, attitude and practices about menstruation among adolescent female in Uttarakhand. Pakistan Journal of Medical Sciences. 2013;3(2):19-22.

7. Sebanti G, Dutta R, Sengupta S. A profile of adolescent girls with gynecological problems. J Obstet Gynecol India. 2005;55(4):353-5.

8. Parwej S, Kumar R, Walia I, Aggarwal AK. Reproductive health education intervention trial. Indian J Pediatr. 2005;72:287-91.

9. Lawan UM, Yusuf NW, Musa AB. Menstruation and menstrual hygiene amongst adolescent school girls in Kano, Northwestern Nigeria. Afr. J. Reprod. Health. 2010;14(3):201-7.

10. Nwankwo TO, Aniebue UU, Aniebue PN. Menstrual disorders in adolescent school girls in Enugu, Nigeria. Journal of Pediatric and adolescent gynecology. 2010;23(6):358-63.

11. Werven IV. Health and hygiene school program initiative for adolescents in Dhaka, Bangladesh. The Journal of Gender and Water. 2012;1(1):34-6. 
12. Sapkota D, Sharma D, Budhathoki SS, Khanal VK, Pokharel HP. Knowledge and practices regarding menstruation among school going adolescents of rural Nepal. Journal of Kathmandu medical college. 2013;2(5):122-7.

13. Haque SE, Rahman M, Itsuko K, Mutahara M, Sakisaka K. The effect of a school-based educational intervention on menstrual health: an intervention study among adolescent girls in Bangladesh. BMJ Open. 2014;4:e004607.

14. Gupta S, Sinha A. Awareness about reproduction and adolescent changes among school girls of different socioeconomic status. J Obstet Gynecol India. 2006;56(4):324-8.

15. Juyal R, Kandpal SD, Semwal J, Negi KS. Practices of menstrual hygiene among adolescent girls in a district of Uttarakhand. Indian Journal of Community Health. 2012;24(2):124-8.

16. Kamath R, Ghosh D, Lena A, Chandrasekaran V. A study on knowledge and practices regarding menstrual hygiene among rural and urban adolescent girls in Udupi taluk, Manipal,India. Global Journal of Medicine and Public Health. 2013;2(4):1-5.

17. Rupa VK, Veena KS, Subitha L, Hemanth Kumar VR, Bupathy A. menstrual abnormalities in school going girls- Are they related to dietary and exercise pattern? Journal of Clinical and Diagnostic Research. 2013;1-4.

18. Salve SB, Dase RK, Mahajan SM, Adchitre SA. Assessment of knowledge and practices about menstrual hygiene amongst rural and urban adolescent girls- A comparative study. International Journal of Recent Trends in Science and Technology 2012;3(3):65-70.

Cite this article as: Ghongdemath JS,

Sidhmalswamy A, Mallapur AA, Shindholimath VV. Impact of adolescent health education on adolescent girls in rural schools and colleges. Int J Reprod Contracept Obstet Gynecol 2016;5:53-7. 